\title{
LA DOCENCIA PARTICULAR Y SU PUBLICIDAD EN EL CÁDIZ DE LAS CORTES (1810-1813)
}

\author{
PRIVATE TEACHING AND ITS ADVERTISING IN THE CÁDIZ DE LAS \\ CORTES (1810-1813)
}

\author{
ENSINO PRIVADO E SUA PUBLICIDADE NO CÁDIZ DE LAS CORTES \\ (1810-1813)
}

\author{
Carlos García Cárdenas \\ Universidad de Cádiz, España \\ https://orcid.org/0000-0002-6093-1486 \\ carlos.cardenas@uca.es
}

Recibido:24/05/2021 Revisado: 26/05/2021 Aceptado: 12/07/2021 Publicado: 29/10/2021

Resumen: El presente artículo ponemos de relieve cómo una buena parte de la sociedad gaditana del momento pide una enseñanza complementaria que sirva, a su vez, para ampliar aquellos conocimientos que vayan más allá del modelo oficial ofrecido por las instituciones. Partiendo de la base del innegable esfuerzo por procurar una enseñanza básica obligatoria, legislado ya en la Constitución de 1812, y cuyo precedente más inmediato lo encontramos en las reformas ilustradas de finales del siglo XVIII, veremos cómo la iniciativa privada será la que intentará cubrir estas carencias. Naturalmente, serán los estratos pudientes, capaces de costearla, quienes apostarán por dicha iniciativa, al tiempo que observamos cómo una serie de disciplinas, dada las características básicamente mercantiles de Cádiz, se irán demandando cada vez con más interés, caso de la enseñanza de idiomas o de nuevas técnicas relacionadas con los estudios de comercio. Independientemente de todo ello, tampoco faltarán aquellas familias que, a título privado, seguirán solicitando la correspondiente atención educativa complementaria para sus integrantes. (vástagos).

Palabras claves: Educación; Prensa; Publicidad periodística; Idiomas; Oferta.

Abstract: This article highlights how a good part of Cadiz society at the time asks for a complementary education that serves, in turn, to expand knowledge that goes beyond the official model offered by the institutions. Starting from the base of the undeniable effort to ensure compulsory basic education, already legislated in the Constitution of 1812, and whose most immediate precedent is found in the enlightened reforms of the late eighteenth century, we will see how private initiative will be the one that will try to cover these shortcomings. Naturally, it will be the wealthy strata, capable of paying for it, who will bet on this initiative, while we observe how a series of disciplines, given the basically mercantile characteristics of Cádiz, will be increasingly demanded with more interest, in the case of language teaching. or new techniques related to business studies. Regardless of all this, there will be no shortage of families who, privately, will continue to request the corresponding complementary educational care for their members. (stems).

Keywords: Education; Press; Journalistics advertising; Languages; Offer. 
Resumo: Este artigo destaca como boa parte da sociedade cadizante da época pede uma educação complementar que sirva, por sua vez, para ampliar conhecimentos que vão além do modelo oficial oferecido pelas instituições. A partir do inegável esforço de garantia da educação básica obrigatória, já legislado na Constituição de 1812, e cujo precedente mais imediato se encontra nas ilustradas reformas do final do século XVIII, veremos como será a iniciativa privada aquela que tentará cobrir essas deficiências. Naturalmente, serão as camadas abastadas, capazes de pagá-la, que apostarão nesta iniciativa, enquanto observamos como uma série de disciplinas, dadas as características basicamente mercantis de Cádiz, serão cada vez mais exigidas com mais juros, no caso de ensino de línguas ou novas técnicas relacionadas aos estudos de negócios. Apesar de tudo, não faltarão famílias que, privadamente, continuarão a requerer os correspondentes cuidados educativos complementares para os seus membros. (hastes).

Palavras-chave: Educação; Imprensa; Publicidade jornalística; Idiomas; Oferta.

Cómo citar este artículo: García-Cárdenas, C. (2021). La docencia particular y su publicidad en el Cádiz de las cortes (1810-1813). Hachetetepé. Revista científica en Educación y Comunicación, (23), 1-13. https://doi.org/10.25267/Hachetetepe.2021.i23.2206

\section{INTRODUCCIÓN}

El liberalismo en España, encarnado paradigmáticamente en la Constitución de 1812, aunque muy incipiente todavía, trajo consigo un deseo de reformas, entre ellas las educativas, que tenían ya su origen en el principio ilustrado del derecho a la enseñanza. Hasta 1767, año en que fueron expulsados de España, los jesuitas, como en el resto del país, llevaron en Cádiz la administración, dirección, selección de maestros y planes de estudios de la enseñanza primaria. Con todo el interés, más bien preocupación, de los ilustrados españoles por la educación y la cultura encontró continuamente una serie de obstáculos de índole diversa que difícilmente posibilitaron, todo lo satisfactoriamente que deseaban, su realización.

Sin embargo, fueron las Cortes de Cádiz las que, por primera vez en España, decretaron a través de la Constitución de 1812 la obligatoria difusión de la enseñanza, al menos la más básica:

En todos los pueblos de la Monarquía se establecerán escuelas de primeras letras, en las que se enseñará a los niños a leer, escribir y contar, y el catecismo de la religión católica, que comprenderá también una breve exposición de las obligaciones civiles (Título. IX, capítulo unico, art. 366).

Consciente del valor de la educación y recién promulgada la Constitución, la prensa gaditana hacía especial hincapié en la necesidad de "un buen plan de educación pública, pues, es necesaria en la infancia la instrucción necesaria sobre las obligaciones y los derechos" (Diario Mercantil, 22-II-1812, p.4). Por contra, la misma Constitución especificaba que el analfabetismo podía ser causa de pérdida de ciudadanía, aunque marcando como fecha tope el año de 1830, en el que "deberán saber leer y escribir los que de nuevo entren en el ejercicio de los derechos de Ciudadano" (Constitución de 1812, título IX, capítulo IV, art.25).

Paradójicamente, al lado de este interés institucional por la mejora de la enseñanza pública, irá apareciendo, por parte de la iniciativa privada, un patente interés por conseguir una mejora de esa educación. A tal efecto, no puede ser más elocuente la aprobación, por parte del Consejo Supremo de Regencia, del proyecto de una Academia 
de Educación presentado "por algunos padres" que, aunque muy atentos a la instrucción y el aprovechamiento de sus hijos, observaban "con el mayor dolor cómo éstos quedaban abandonados luego que salen de las escuelas de primeras letras" (Diario Mercantil, 29-I-1812, p. 4).

Asimismo, a partir de aquí, coincidiendo con el auge de la prensa a raíz del decreto de libertad de imprenta de 10 de noviembre de 1810, veremos cómo proliferarán en los periódicos gaditanos una variada y bien publicitada oferta relativa a la iniciativa particular, cuando no dentro del ámbito meramente privado.

\section{METODOLOGÍA}

El objetivo, pues, no será otro que exponer, partiendo de la base de lo que podríamos denominar un cuestionamiento de la enseñanza pública, toda una serie de propuestas, variadas e innovadoras, capaces de suplir las carencias derivadas de aquella. Para ello nos basaremos, acorde con el título a que responde el artículo, en una metodología consistente en mostrar, siguiendo esa compleja interacción ofertademanda que nos ofrece la prensa gaditana del momento, toda una serie de anuncios y artículos relacionados con ese propósito de extender la enseñanza, en principio básicamente obligatoria, a cotas más ambiciosas y de mayor calidad.

También, pondremos de relieve aquellos intentos reformadores previos de la anterior centuria y que obedecían al mejor espíritu ilustrado. Pero, en definitiva, será la publicidad el principal objeto de nuestro estudio, precisamente en estos años de principios del siglo XIX en la que irá adquiriendo cada vez un mayor protagonismo, al albur, precisamente de la libertad de imprenta propiciada por las Cortes de Cádiz y que nació oficialmente por el decreto de 10 de noviembre de 1810. Por extensión, será también la prensa la que pondrá de relieve la importancia de la escuela como el vehículo más apropiado para inculcar las nuevas ideas constitucionales. En definitiva, un nexo de unión entre la sociedad y sus gobernantes (Labio Bernal, 2009, p. 68).

Respecto a la bibliografía, que se acompaña al final junto con obras al uso de referencia en este periodo, hemos de matizar que, en cuanto a lo que entendemos como un planteamiento de la enseñanza alternativa a la oficial, hemos observado que es un apartado todavía por investigar en profundidad. En consecuencia, es la prensa quien nos ha servido más bien como principal fuente documental, a falta de una bibliografía más específica. Precisamente, en mayo del año 2021, la Universidad de Cádiz ha publicado Evolución de la enseñanza privada en el Jerez del siglo XIX, de José Luís Sánchez Villanueva, que es de gran interés a la hora de plantear un análisis comparativo con el caso gaditano que no entra en el objeto de estudio de este artículo.

Con todo, la investigación es de corte documental, con una clara intención: la de seleccionar, organizar e interpretar información vinculada a la cuestión que es objeto de estudio (Ahmed, 2010). En este sentido, las fuentes del presente estudio son principalmente primarias e impresas (fundamentalmente prensa escrita), ya que son aquellas que ofrecen información original y relevante de primera mano. Igualmente, cabría señalar que los criterios de selección de las fuentes han sido: desde la autenticidad a la credibilidad, pasando la verificación de las mismas, que vienen a contribuir en la relevancia y significado de la investigación en foco (Bernal et al., 2008).

Una investigación de corte cualitativo que se inspira en el siguiente procedimiento: desde la búsqueda y análisis de la documentación, a una segunda fase inspirada en la estructuración e interpretación. Con ello, el resultado es un trabajo 
documental de tipo histórico, en la medida que se pretende comprender un fenómeno histórico, centrada en el interés por conocer y entender el pasado, siendo éste un fenómeno social, educativo y cultural, por lo que adquiere una dimensión de investigación documental cualitativa. Algo que lo hacemos coincidir con las preocupaciones éticas de este tipo de estudios (De la Torre y Navarro, 1990). En definitiva, con el estudio documental se promueve un paso cualitativo de la información atesorada en los documentos al conocimiento visible y ordenado (González, 1979; Rodríguez, 2006).

\section{RESULTADOS}

\section{1. Los primeros intentos renovadores}

Así, desde el último cuarto del siglo XVIII, hubo una progresiva aceptación de los métodos de enseñanza más en boga del momento, como lo demuestra la orden municipal que implantó el llamado método de Servidori en prácticamente todas las escuelas de la ciudad en 1792, al tiempo que se imponía el aprendizaje de los principios religiosos, preferentemente con el catecismo de Fleuri. Especial atención se prestó a la gramática según el tratado que la Real Academia de la Lengua publicara en 1796 (Espigado, 1996). Ya en los sainetes del gaditano Juan Ignacio González del Castillo (1763-1800), donde se ridiculizan muchas capas de la sociedad de su tiempo, precisamente no se ahorraban críticas a la incultura y al oscurantismo (Sala Valdaura, 1996, p. 219).

Fue a partir de 1799 cuando se estableció el Colegio Académico de Primera Educación, con la doble finalidad de evitar cualquier tipo de intromisión profesional y de mejorar la calidad del servicio docente. Bajo la presidencia de Manuel José Quintana nació la Dirección General de Estudios, que podemos considerar el embrión de los futuros Ministerios de Educación (Ruiz Beirro, 1970). A pesar de todo, al menos en lo que pudiéramos considerar una "educación esmerada", era frecuente recurrir a docentes particulares. Por los datos consultados, no parece que este tipo de enseñanza, aplicada en estos primeros años del siglo XIX, arrojara malos resultados en Cádiz, pues se calcula que el $47 \%$ de los niños entre 6 a 12 años asistía a clase en 1801, siendo curiosamente las niñas las que presentaban un porcentaje aún mayor, el $52 \%$. Estas cifras, incluso, fueron subiendo algo más en torno a 1818 (Román, 1991, p. 59). Respecto a la potencial población en edad escolar de estos años de las Cortes que historiamos (1810-1813), sabemos que en 1801 el número de habitantes de Cádiz comprendidos entre 0 a 19 años era de 19.573, de un total de 57.837 (Pérez Serrano, 1992, p. 112). Aún así, es preciso reconocer que, en términos generales, España a lo largo de todo el siglo XIX quedó manifiestamente descolgada de la lista de países europeos que poseían un aceptable grado de alfabetización (Espigado, 1990, p. 175).

Dicha enseñanza corría a cargo de los llamados maestros de primeras letras, estando muy en boga entonces el método de Pestalozzi, que se basaba en la intuición como la principal fuente de conocimiento, al tiempo que se cuestionaban otros métodos ya experimentados con anterioridad, sobre todo, en el modo de ser tratados los niños, en clara alusión reprobatoria a los jesuitas. El diario El Conciso $(1811$, p. 4) expresaba la necesidad de que desaparezca entre nosotros el anatema gótico- bárbaro "la letra con sangre entra", así como una cierta crítica anticlerical que apostaba porque los religiosos de dedicaran a sus cometidos espirituales y no tanto a los docentes: "¿Por qué los eclesiásticos no se dedican a tan propio ministerio?” (El Conciso,1811, p. 4) 
Por lo demás, en Cádiz era bastante alto el número de escuelas desde principios de siglo, a las que había que añadir las que impartían estudios de latinidad, dos colegios y dos academias de Ciencias, según se desprende de la Relación de gremios de 1801. En 1804 se fundaría la Academia de Matemáticas y Comercio, consecuentemente motivada por ser Cádiz una ciudad eminentemente comercial, y ocho años después se abriría otra en la Plaza de Viudas. Posteriormente, en 1822 la Sociedad Económica Gaditana de Amigos del País, presentó a las autoridades locales un ambicioso proyecto renovador de estos estudios de Comercio por valor de 45000 reales anuales que no pudo materializarse por falta de medios (García León, 1990, p. 256).

\subsection{Una motivación creciente}

Paradójicamente, llama la atención cómo en estos mismos años se pida insistentemente otro tipo de docencia, capaz de suplir las carencias que se derivaban de esa enseñanza elemental y gratuita. Lógicamente, un planteamiento así solo podría provenir de las clases sociales más pudientes, que exigirán una educación complementaria y obviamente de "mayor calidad", acorde con su estatus socioeconómico. Para hacernos una idea de la estructura laboral de entonces, en 1813 el 74.05 de la población activa de Cádiz se dedicaba al sector terciario, frente al 24.27 del secundario y al 1.68 del primario (Pérez Serrano, 1992, p.162).

Sin embargo, conviene matizar que este tipo de enseñanzas, complementarias o al margen de las oficialmente instituidas, no constituían por supuesto novedad alguna. Dentro de los privilegios regios concedidos al gremio de maestros durante el siglo XVIII, ya se contemplaba la posibilidad de que particulares abrieran escuelas, aunque con su debido permiso y bajo estricta vigilancia (Azcárate, 1993).

Así, Antonio Alcalá Galiano en sus "Memorias" no duda en reconocer que "todos mis estudios eran domésticos", llegando hasta a vanagloriarse de ser uno de los pocos hombres "de cierta importancia en España" en tener "la carrera menos literaria". Por contra, nos refiere cómo las primeras noticias sobre la muerte de su padre en la batalla de Trafalgar (1805) las aportó su hermana, "que asistía a una academia de niñas" (Alcalá Galiano, 1955, p. 304).

Todo ello se hizo bien patente al menos en el ámbito de la Baja Andalucía, como consecuencia en buena parte por la falta de ejecución de los ordenamientos jurídicos, que, aunque bien diseñados, se enfrentaron a los intereses de clases, cuando no a la desgana e incuria oficial u oficiosa, así como a una estructura sociopolítica muy difícil de cambiar (Ruiz Lago, 1974).

\subsection{Las academias privadas}

Aunque no es objeto de este trabajo un estudio pormenorizado de las academias particulares de enseñanza en Cádiz durante estos años, valgan algunos casos que bien pudieran tomarse como ejemplos al uso. De especial relevancia destaca la Academia ubicada en de la calle del Rosario número 109, en la que se enseñaba a leer, escribir, contar, la lengua española, la latina y también lecciones de inglés. En su anuncio correspondiente, aparecido en el Diario Mercantil (30-III-1810), se observa ya una serie de mensajes propios de lo que consideraríamos unas incipientes técnicas publicitarias. Así, podemos leer textualmente que, en dicha Academia "se enseña con la misma facilidad al que ha estudiado que al que no, al hombre ocupado que al joven" (Diario Mercantil,1810, p. 4). También, en referencia al mismo establecimiento, el diario El 
Conciso (22- IX-1810) en su publicidad señalaba el coste de las clases en 6 pesos mensuales.

Un sentido mixto en sus enseñanzas, con ciertas variantes, vemos en la Academia de la Casa de la Camorra, que educaba jóvenes con vocación militar y en la que, junto a las clases generales y al precio de 160 reales mensuales, "había también materias militares como dibujo militar, ordenanzas militares, fortificaciones, ejercicios de infantería y táctica general, pasando por retórica, música y piano" (Diario Mercantil, 21I- 1811). Aun así, no será hasta el segundo tercio del siglo XIX cuando se irá creando en Cádiz algunos centros de enseñanza de mayor entidad, cuya mejor expresión será el Colegio de San Felipe - Imagen 1-. Ello irá unido no sólo al mayor esmero burgués por la educación, sino, también, a la presencia de pedagogos competentes y vocacionales como Alberto Lista o Arbolí.

Imagen 1. Colegio San Felipe Neri

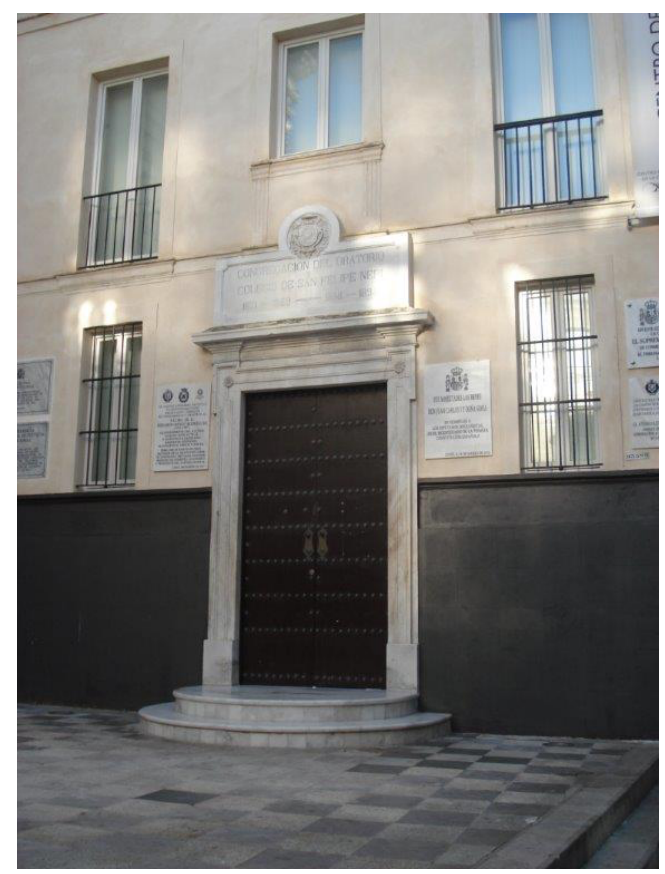

\subsection{Los ofrecimientos de particulares}

Junto a estas academias aparecen numerosos anuncios donde particulares, con alguna especialidad o habilitación determinadas, también se publicitan. Esta oferta, al margen de la perentoria necesidad de buscarse un cierto sustento en la mayoría de los casos, también se explica en parte por el deseo de ciertas familias de procurar individualmente la educación de sus hijos. Además, en los años de las Cortes y durante el asedio de la ciudad (1810-1812) hubo un notable número de emigrados, muchos de ellos con la debida formación. Por lo general se trata de personas con título previo o bien pertenecientes a academias, algunas de ellas de cierto renombre, según afirman a la hora de anunciarse.

De esta forma, se dio paso a una curiosa demanda - oferta de tales personas, de la que la publicidad se hizo el debido eco. Valgan, pues, algunos ejemplos extraídos del Diario Mercantil: 
Doña María del Carmen Jaén, directora aprobada por el Gobierno, hace saber al Público: tener establecida su clase de educación en la calle de la Amargura esquina a la del Sacramento casa núm. 20 del cuerpo principal, en la que se propone enseñar (Diario Mercantil, 11- II- 1812, p. 4).

Un joven de 22 años profesor de humanidades, individuo de algunas academias, solicita algún acomodo en un escritorio o bien para instruir algunos jóvenes a los que dará algunos principios de matemáticas y bellas letras. En el puesto del diario calle de la Carne $\mathrm{n}^{\mathrm{o}} 1$ (Diario Mercantil, 15- IX-1811, p. 4).

En la calle de la portería de Capuchinos 147, vive D. José Pérez, quien solicita una persona capaz de enseñar la táctica militar de infantería (Diario Mercantil, 11-V-1812, p. 4).

Se desea saber en la Real Isla de León de un maestro que quisiera encargarse de dar lecciones particulares de francés y enseñar a hablarlo. En la librería de la calle Mayor de dicha Isla darán razón de los sujetos que desean estudiarlo (Diario Mercantil, 14-X-10, p. 4).

Una variante digna de ser mencionada aparte, dentro de este abigarrado elenco, supone la figura del ayo o preceptor, a medio camino entre la enseñanza y el sirviente distinguido a domicilio, propia de clases acomodadas, suele encontrarse a veces en la oferta publicitaria gaditana, aunque, con cierta lógica, los casos consultados coinciden con clérigos, que, por lo general, se sirven de esta actividad básicamente como medio de subsistencia - Imágenes 2 y 3 -

Un sacerdote que se halla desvalido solicita acomodo en alguna casa decente para ayo de algunos niños, les enseñará a leer, escribir, cuentas, gramática y cuanto pertenezca a una educación cristiana. Dará razón el Padre sacristán mayor de los reverendos padres Dominicos (Diario Mercantil, 6-VII- 1811).

Un sacerdote desea colocarse en alguna casa decente para maestro o ayo de algunos niños, les enseñará cuanto conduzca a una educación cristiana y demás principios propios de la juventud, el que lo necesite acudirá a los pabellones de la Bomba, en casa de la Sra. viuda del gobernador que murió en la defensa de Badajoz (Diario Mercantil, 29- VI- 1812, p. 4). 
Imagen 2. Diario Mercantil, 6- I- 1812

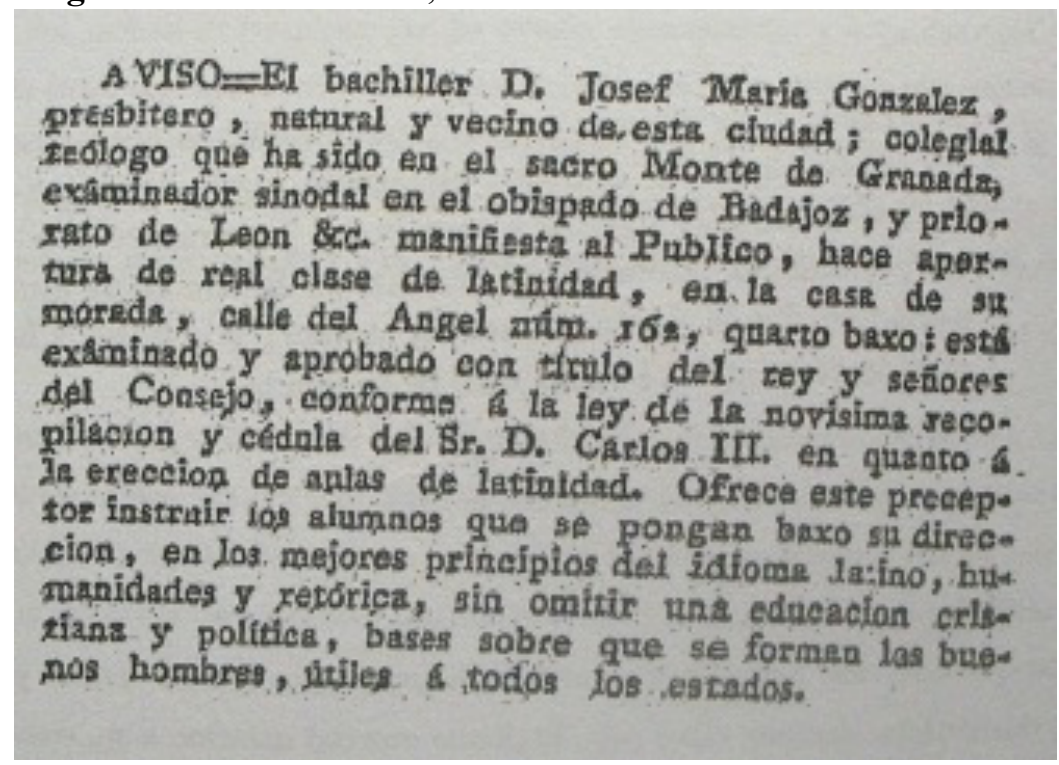

Imagen 3. Diario Mercantil, 3- IV- 1812

OTRO. Ios sugetos que quieran enseñar $\{$ sus niños en su casa á leer, escribir, elementos matemáticos como son arimétics, álgebra y geometría, juntamente música y. gramática latina, pueden avisar en la oficina de este periódico donde darén razon del sugeto, $y$ acudirá á la casa de cada uno á la hora qua se le ser̃ale.

\subsection{Unas enseñanzas muy demandadas}

\subsubsection{Los idiomas}

Especial interés tendrán los idiomas en una ciudad mercantil donde el estudio de las lenguas modernas, básicamente francés e inglés, eran poco menos que materia obligada en las casas comerciales gaditanas. La calle Nueva, centro comercial de la ciudad, que desembocaba en la populosa plaza de San Juan de Dios, tenía fama de ser una pequeña babel en la que se hablaban todos los idiomas. Así lo refiere un testigo directo: "se dice comúnmente que la lengua que menos se habla es la española, por la multitud de capitanes de barcos mercantes y otros muchos extranjeros de todas las naciones que allí se juntan" (Cruz, 1997, p. 361).

Los anuncios alusivos a esta práctica de aprender idiomas irán desde la publicidad sobre gramáticas inglesas hasta el ofrecimiento de docentes de lenguas extranjeras, pasando por los ofrecimientos y solicitudes de los siempre socorridos traductores:

Gramática para aprender por nuevo método la lengua inglesa, por Don Jorge Shipton. Se hallará en la librería de Castillo, calle san Francisco; en la de 
Carreño, calle Ancha, y en partidas en casa del autor, calle del Hospital de Mujeres, núm. 164, cuerpo segundo (Diario Mercantil , 24-IV-1812, p. 4).

Cualquier caballero literario español que pueda traducir un pequeño tratado público del idioma inglés al castellano, dejará una esquela (con su nombre y cada dónde habita). En la calle de la Carne 186 darán razón (Diario Mercantil, 10-I-1811, p. 4).

En el almacén de la calle Nueva, debajo del café León de Oro, dará razón su dueño D. Antonio Arana de un sujeto que traducirá todo género de papeles y cuentos del inglés al castellano, o de éste al inglés (Diario Mercantil, 17-II-1811, p. 4).

Hasta se dará el caso de determinados extranjeros que, ofreciéndose para tareas domésticas, harán mención a sus conocimientos de idiomas:

Un joven alemán, que sabe además de su lengua, la francesa, la inglesa y la española, solicita acomodo para servir, ya sea en esta ciudad o fuera de ella, en clase de ayuda de cámara, mozo de comedor u otra clase, aunque sea en alguna posada, tiene personas que lo abonen; darán razón en la posada del Cañón de oro, calle de Comedias (Diario Mercantil, 3- XI- 1813, p. 4).

"Un individuo de nación inglesa solicita acomodo para ayuda de cámara, lo que desempeña a toda satisfacción. En la imprenta de este periódico darán razón" (Diario Mercantil, 4-VII-1810, p. 4).

\subsubsection{Una publicidad muy a la moda: la taquigrafía}

Paulatinamente, fueron apareciendo nuevos sistemas de educación y formación al margen del tradicional aprendizaje, sobre todo para satisfacer las necesidades de las clases mercantiles, de tal manera que a principios del siglo XIX empezaron a surgir toda una serie de establecimientos educativos tendentes a proporcionar los conocimientos básicamente necesarios. Junto con la enseñanza de los idiomas, como ya hemos visto, preferentemente el inglés, será la taquigrafía uno de estos nuevos aprendizajes más en boga.

Curiosamente, para que nos hagamos una idea de esta necesidad, baste decir que, entre las muchas carencias, tanto de tipo organizativo como de medios, con que se enfrentaron las recién inauguradas Cortes desde su apertura el 24 de septiembre de 1810 en la Isla de León, figura la de los taquígrafos. Algo que, en principio no se previó y que, por su funcionalidad tan específica, tendrá una especial importancia a la hora de recoger lo más fielmente posible los debates parlamentarios en sus correspondientes actas. La ausencia inicial de taquígrafos fue motivo de serias quejas por parte de los diputados que veían cómo en muchas ocasiones sus intervenciones no eran recogidas con las suficientes garantías de exactitud en lo dicho. Valga, pues, este episodio de los inicios del parlamentarismo español para poner de relieve la importancia de la taquigrafía entonces. Curiosamente, aparecieron en la prensa en esos momentos diversos anuncios publicitando su enseñanza, aunque por las fechas que barajamos no podemos considerar que tales anuncios coincidieran precisamente con este episodio referido de las Cortes, dado que algunos de estos anuncios son anteriores al inicio de las mismas.

No debió ser tarea fácil encontrar taquígrafos en Cádiz, pues suponemos que se trataba de una práctica de uso poco extendido. De ahí que, si nos remitimos a la prensa del momento, vamos a comprobar cómo irán apareciendo anuncios ofreciendo cursos de 
taquigrafía a la par que se alababa las ventajas y utilidad de la misma. Uno de los métodos taquigráficos más en boga entonces era el de Francisco Martí, que en la Guía de Cádiz para 1813 aparece como taquígrafo en las Cortes. Fue su discípulo más directo, Ramón Escolar, quien escribió por esos años una Taquigrafía Castellana que venía a. perfeccionar los cursos de su maestro Martí (Rossell, 1960).

Sin embargo, otro método alternativo, el de Manuel Risueño, se anunciaba también justamente cuando las Cortes aprobaron la presencia de taquígrafos, exponiendo "las grandes ventajas que tiene este método sobre todos los adoptados hasta el día en nuestra Península". Igualmente, garantizaba la exactitud en lo escrito, así como "la claridad en su lectura", lo que le permitía publicitarse con las suficientes garantías, "por lo breve y fácil de sus reglas y por la velocidad en su ejecución".

Se abre suscripción a un nuevo curso de taquigrafía de D. Manuel Risueño. Aunque el principal objeto es la enseñanza de este arte, lo es también hacer conocer al público las grandes ventajas que tiene este método sobre todos los adoptados hasta el día en nuestra Península (Diario Mercantil, 12- XII-1810, p. 4)

Previamente a este anuncio, resulta curioso lo que podríamos denominar intentos de dignificación social de la profesión de taquígrafo, según se desprende de este otro anuncio de curso, esta vez de un tal Guillermo Jaramillo, quien, a su denominación de "catedrático", adjunta la de "caballeros alumnos" a sus potenciales discípulos (Diario Mercantil, 26- VIII- 1810, p. 4).

A partir de dicho anuncio se irán sucediendo otros de las mismas o similares características, incluso con distintas modalidades de remuneración, que a veces pudieran lindar con una publicidad engañosa - Imagen 4-:

Curso de taquigrafía, o sea, arte de escribir tan pronto como se habla, se aprende sin ayuda de maestro. El que quiera hacerse con esta taquigrafía acudirá con precisión dentro de seis días a recoger el recibo de 20 rs. ejemplar al refino que está al frente de la confitería de la puerta última de la calle San Francisco (Diario Mercantil, 5-V-1811, p. 4).

Hasta el 15 del corriente se admitirán alumnos al curso gratuito de taquigrafía que se abrió el 2 del corriente en casa del profesor Moya, calle Nueva. Se previene que los que no gusten optar al premio ofrecido al más sobresaliente quedan exceptuados de contribuir con los tres pesos fuertes señalados para el fondo que debe constituir el citado premio (Diario Mercantil, 6- XI- 1810, p. 4). 
Imagen 4. Diario Mercantil, 26-VIII-1810

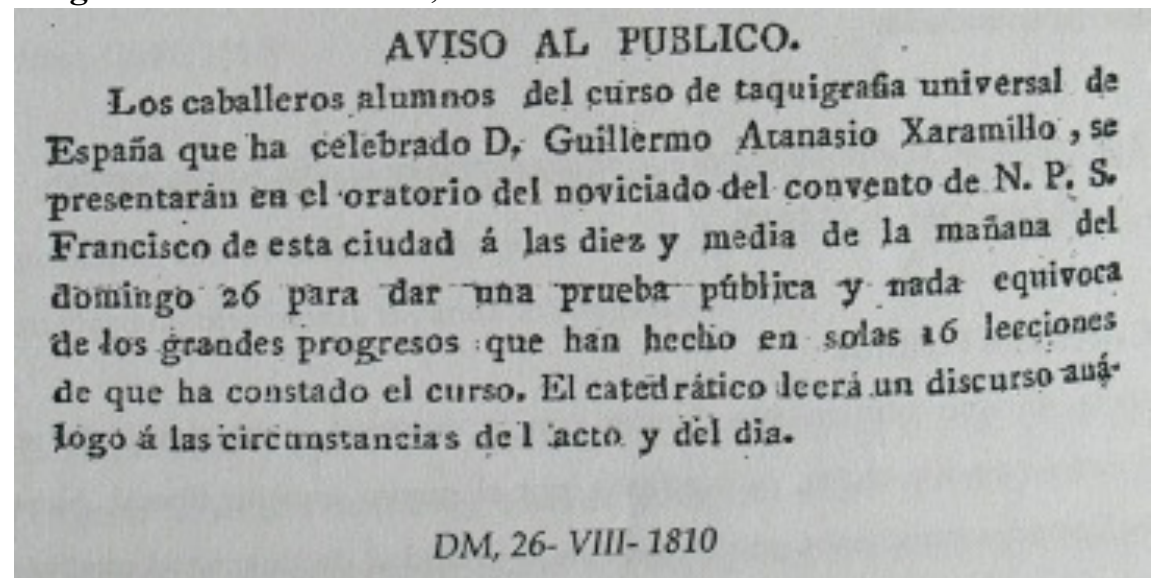

\section{CONCLUSIONES}

A tenor de la información consultada en la prensa gaditana del momento, Diario Mercantil (1810-1813), en lo referente a la cuestión educativa, se desprenden las siguientes conclusiones:

El que aparezcan en sus páginas unas ciento veintiocho alusiones a dicha cuestión en esos años se debe principalmente a factores de tipo político unos y de tipo coyuntural otros. En primer lugar contamos con el decreto de las Cortes declarando obligatorio el establecimiento de "escuelas de primeras letras en todos los pueblos de la Monarquía", lo que supone por primera vez en nuestra Historia un intento gratuito de generalizar la enseñanza, si bien en sus fases más elementales. En segundo lugar, contamos con un segundo decreto de las Cortes, el de libertad de imprenta, que supuso un considerable avance en la comunicación e información de una opinión pública que, por primera vez, tenía acceso a un buen número de noticias y artículos de fondo de los que antes había carecido. Todo ello dentro de los límites que imponían una determinada censura mucho más permisiva y los altos índices de analfabetismo ya expresados.

La oferta docente a través de los diferentes anuncios será de lo más variada, desde anuncios de academias privadas hasta ofrecimiento de particulares (muy considerables), pasando por manuales para el estudio de las más diversas materias (eran numerosas las librerías existentes en Cádiz). Esta información pone de relieve, asimismo, la importancia que en estos inicios del periodismo va a ir adquiriendo la publicidad como un apartado propio dentro del diseño de los periódicos, aunque, dentro de este contexto, será el Diario Mercantil quien muestre unas características más propias del periodismo al uso. Dicha información, en un $90 \%$, corresponderá a lo que podemos entender como sector privado.

Aún así, no debemos interpretar todas estas soluciones docentes como una alternativa a las reformas institucionales en materia de enseñanza, habida cuenta de que prácticamente no hubo lugar a que fueran llevadas a cabo en su totalidad por una serie de circunstancias ajenas a ellas mismas. La Guerra de la Independencia y la posterior reacción absolutista en 1814 dieron al traste con todo ello.

Siempre hubo una enseñanza privada esmerada y exigente, propia de los sectores sociales más pudientes, destinada a la perpetuación de una clase dominante y destinada a ejercer en la sociedad un papel determinante. Para esta clase la enseñanza propiamente pública quedará como un modelo, más o menos, ajeno. Ayudará a comprender mejor 
esta observación el hecho de que Cádiz fuera una ciudad eminentemente portuaria y mercantil y el que en la ciudad hubiera por estos años una alta población flotante como consecuencia de la guerra contra Francia, calculándose en un tercio superior a lo habitual, según los estudios demográficos ya expresados. Esta última consideración tiene su natural reflejo en la prensa, habida cuenta de que entre 1811 y mediados de 1812 extraemos la mayor parte de la información (60\%). A partir de la segunda mitad de 1812, una vez que se levanta el sitio de Cádiz por las tropas napoleónicas, dicha población flotante disminuye y también lo hará la oferta educativa privada.

Por su parte, esa cualidad portuaria de la ciudad y su burguesía de negocios se pone también de relieve en su interés por fomentar los estudios de comercio e idiomas como disciplinas docentes, que se verán potenciadas desde el sector privado como se deduce de la información aportada.

Con todo, todas estas conclusiones, que tienen como principal fuente de conocimiento la prensa de la época, está necesitada, en lo que la caso gaditano respecta, de un trabajo en profundidad que ponga debidamente de relieve hasta qué punto, cuantitativa y cualitativamente, la enseñanza privada ejerció su función más allá de la información meramente periodística.

FINANCIACIÓN. Esta investigación no recibió ninguna financiación externa.

\section{REFERENCIAS BIBLIOGRÁFICAS}

Ahmed, J. (2010). Documentary Research Method: New Dimensions. Indus Journal of Management \& Social Science (IJMSS), (4), 1-14.

Alcalá Galiano, A. (1953). Memorias (Obras Escogidas). Biblioteca de Autores Españoles.

Azcárate, I. (1993). Historia escolar de Cádiz (1564-1767) o raíces de un pueblo. Revista Tavira, (10), 19-94.

Bernal, S., Martínez, M., Parra, A., y Jiménez, J. (2015). Investigación documental sobre calidad de la educación en instituciones educativas del contexto iberoamericano. Revista Entramados- Educación y Sociedad, 2(2), 107- 124.

Cruz, N. (1997). Viaje de España, Francia e Italia, t. XIII. Cádiz. Servicio de Publicaciones de la Universidad de Cádiz.

De la Torre, E., y Navarro, R. (1990). Metodología de la investigación, bibliográfica, archivista y documental. Mc.Graw-Hill.

Diario Mercantil de Cádiz. (1810-1813). Periódico, Archivo Histórico Provincial de Cádiz.

El Conciso. (1813). Periódico, Archivo Histórico Provincial de Cádiz.

España. Constitución de 1812.

Espigado, G. (1990). Aprender a leer y escribir en el Cádiz del Ochocientos. Universidad de Cádiz.

Espigado, G. (1996). El analfabetismo en España. Un estudio a través del Censo de 1877. Revista Trocadero, (2), 251-261.

García León, J. M ${ }^{\mathrm{a}}$ (1990) Educación y enseñanza en Cádiz durante el Trienio Constitucional (1820-1823). Revista Trocadero, (2).

González, S. (1979). Manual de redacción e investigación documental. Trillas.

Labio Bernal, A. (2009). Estructura, Historia y Actitudes del Periodismo Gaditano. De sus origenes a la actualidad. Quorum. 
Pérez Serrano, J. (1992). Cádiz, la ciudad desnuda. Universidad de Cádiz.

Relación de Gremios. (1801). Cádiz.

Rodríguez, I. (2006). Técnicas de investigación documental. MAD.

Román Guerrero, R. (1991). La educación en Cádiz en el siglo XVIII. Unicaja.

Rossell, A. (1960). La taquigrafía en las Cortes de Cádiz (1810-1813). Edición privada.

Ruiz Berrio, J. (1970). Política escolar de España en el siglo XIX (1800-1833). Consejo Superior Investigaciones Científicas.

Ruiz Lago, M. (1974). Ilustrados y reformadores en la baja Andalucía. Editora Nacional.

Sala Valdaura, J. (1996). Los sainetes de González del Castillo en el Cádiz de finales del siglo. Fundación Municipal de Cultura. 